\title{
Parietal Cranium Bifidum: A Rare Presentation
}

\author{
${ }^{1}$ Sivakami Rathinam, ${ }^{2}$ Rameshkumar Rudrappa, ${ }^{3}$ Bhavishya Talluri
}

\section{ABSTRACT}

Aim: To enlighten the readers regarding rare and distinct presentation of fetal encephalocele in parietal location and its significance.

Background: Cranium bifidum is a defect in the cranium through which there can be herniation of intracranial contents. If the content of herniation is meninges, it is called meningocele and if it contains brain tissue in addition to meninges, it is called meningoencephalocele or encephalocele. The incidence of encephalocele is 1 in 4,000 live births. The most common location is the occipital region (75\%) followed by frontoethmoidal (15\%), which is common in Asian population, and rarest is the basal followed by parietal locations. The exact incidence of parietal encephalocele is not available due to its rarity.

Case report: We present a case of a 24-year-old primigravida female in second trimester who came for antenatal scan to rule out anomalies. On examination by ultrasonography, we found a large cerebriform soft tissue herniating through a defect in skull vault from the vertex region with secondary microcephaly.

Conclusion: Here we give an overview of rarest form of encephalocele in parietal region, which grossly differs from the already reported parietal encephaloceles of atretic type presenting as small skin-covered subscalp lesions that contain Meninges and neural and glial rests. In our case, the encephalocele was distinct, being larger in size with normal brain parenchyma as the major content of the herniating sac.

Clinical significance: Only few cases of parietal encephalocele is reported in the literature, that too of atretic type. Apart from being the rarest form, this variant is found to be associated with poor prognosis.

Keywords: Magnetic resonance imaging, Parietal encephalocele, Rare presentation, Ultrasound.

How to cite this article: Rathinam S, Rudrappa R, Talluri B. Parietal Cranium Bifidum: A Rare Presentation. Int J Infertil Fetal Med 2017;8(1):41-44.

\section{Source of support: Nil}

Conflict of interest: None

Date of received: 10-9-2016

Date of acceptance: 15-10-2016

Date of publication: May 2017

\footnotetext{
${ }^{1}$ Assistant Professor, ${ }^{2}$ Professor and Head, ${ }^{3}$ Postgraduate Student

${ }^{1-3}$ Department of Radiodiagnosis, Sri Manakula Vinayagar Medical College and Hospital, Puducherry, India
}

Corresponding Author: Sivakami Rathinam, Assistant Professor, Department of Radiodiagnosis, Sri Manakula Vinayagar Medical College and Hospital, Puducherry, India Phone: +914132643000, e-mail: drsivakamijj@gmail.com

\section{BACKGROUND}

Encephalocele is a type of cephalocele where there is herniation of intracranial tissue through a congenital defect in the cranium. ${ }^{1}$ It is thought to occur secondary to failure of closure of the neural tube at 24 days of intrauterine gestation. It accounts for approximately 1 per 4,000 live births. They are located in the midline, with occipital region (75\%) being the most common location. Other less common locations include frontoethmoidal encephalocele, nasal encephalocele (15\%), basal encephalocele, and parietal encephalocele. ${ }^{1}$ The encephaloceles in parietal region are rare in occurrence and usually are seen as atretic midline scalp masses. The exact incidence of parietal encephalocele is not available due to its rarity. Only few cases of parietal encephalocele are reported in the literature, that too of atretic type. Apart from being the rarest form, this variant is found to be associated with poor prognosis. Atretic encephaloceles are small, skin-covered subscalp lesions that contain meninges and neural and glial rests with high incidence of venous and midline anomalies. ${ }^{2-4}$ Here we give an overview of peculiar form of parietal encephalocele because of its rarity and large size differing from the atretic variety.

\section{CASE REPORT}

A24-year-old primigravida female in her second trimester presented to the Radiology Department for antenatal scan to rule out anomalies. The patient was not on folic acid during her course of pregnancy. Her hemoglobin level was $7.8 \mathrm{mg} / \mathrm{dL}$, and random blood sugar $171 \mathrm{mg} / \mathrm{dL}$. On obstetric and gynecologic evaluation, the patient was not a known case of hypertension. The fundal height approximated the level of umbilicus. Dating scan was not performed.

On ultrasound examination using GE Voluson S6, there was demonstration of single live intrauterine gestation with fetal biometry (Table 1 and Graphs 1A to D). Biparietal diameter and head circumference demonstrated

Table 1: Overview of the biometric parameters

\begin{tabular}{llll}
\hline Biometry & Size $(\mathrm{mm})$ & Weeks & Days \\
\hline Biparietal diameter & 33 & 16 & 3 \\
Head circumference & 132 & 16 & 6 \\
Abdominal circumference & 160 & 21 & 1 \\
Femur length & 31 & 19 & 6 \\
\hline
\end{tabular}




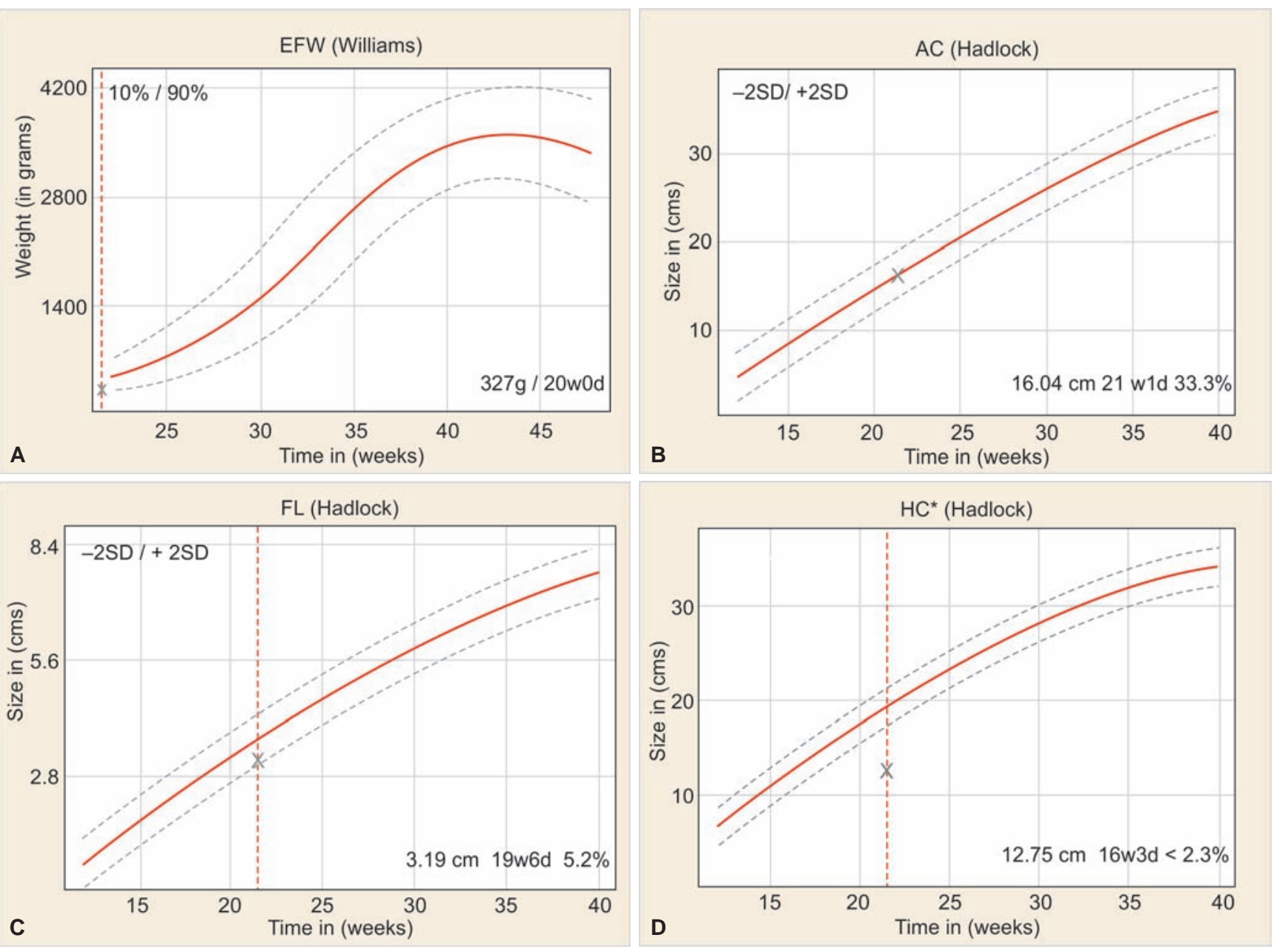

Graphs 1A to D: Growth charts show microcephaly as revealed by head circumference less than 2 standard deviation

values less than 2 standard deviations of normal range representing microcephaly. Abdominal circumference and femur length demonstrated values within 2 standard deviations of normal range. Placenta was placed anteriorly with grade I maturity and it was not low lying. Liquor was adequate. Umbilical cord showed three vessels, namely two umbilical arteries and one umbilical vein. Cord around the neck was noted (Fig. 1). Estimated fetal weight was $327 \pm 48 \mathrm{gm}$. Average ultrasound gestational age was 18 weeks and 4 days.

There was a large cerebriform soft tissue measuring $5.4 \times 2.6 \mathrm{~cm}$, seen herniating through a midline defect in the skull vault (width $=1.25 \mathrm{~cm}$ ) at the vertex region. No cystic areas were noted in the herniation (Figs 2 and 3). There was no evidence of hydrocephalus or spina bifida. Generalized facial and scalp edema was seen, which was probably due to compression effect of cord around the neck (Fig. 4). The diagnosis made was large parietal encephalocele with secondary microcephaly.

Termination of the pregnancy was suggested to the patient by the obstetrician considering the large size of the herniation through the cranial defect with

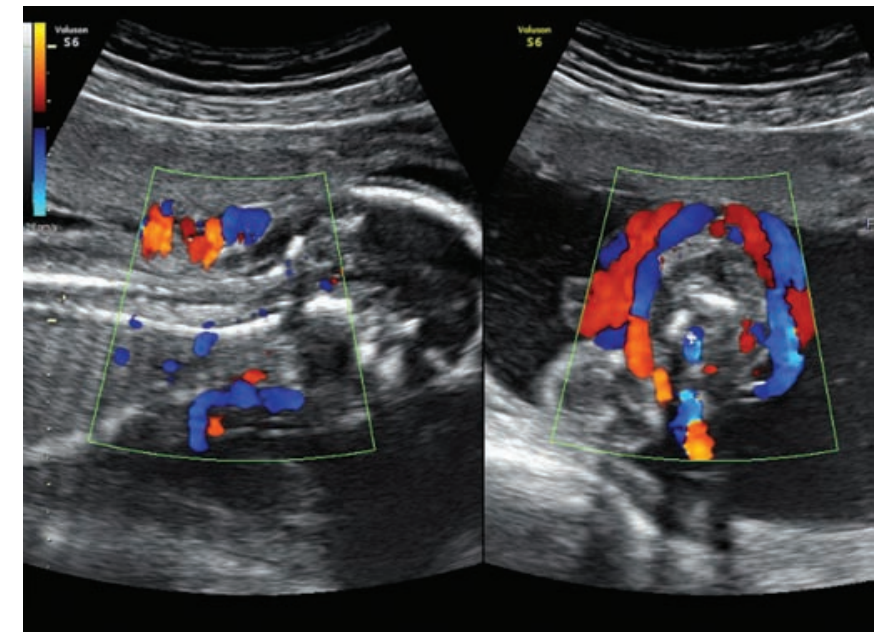

Fig. 1: Ultrasonography image on color Doppler shows cord around the neck

resultant microcephaly, though no associated anomalies were found.

After expulsion, the gross images of pathologic specimen were taken. It revealed a large soft tissue swelling in the scalp at vertex region and a small sized head. There was evidence of scalp and facial congestion and edema. 


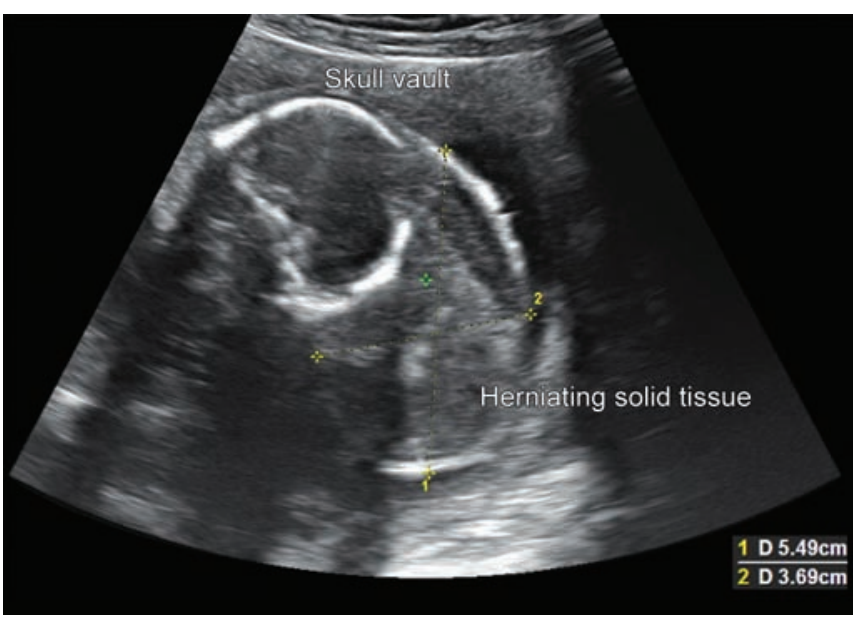

Fig. 2: Ultrasonography image reveals a herniating cerebriform content arising from the parietal aspect through the cranial defect

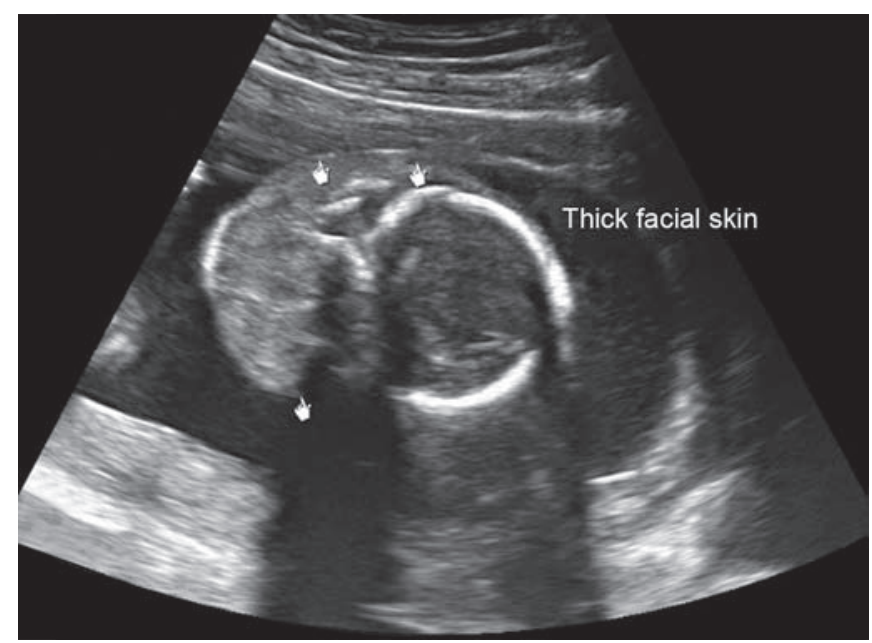

Fig. 4: Ultrasonography image reveals thickened facial skin and scalp

There was no soft tissue swelling along the back. The extremities and digits were normal (Fig. 5). On X-ray images (anteroposterior and lateral), there was evidence of a large soft tissue swelling of scalp with a cranial defect of size $1.1 \mathrm{~cm}$ at the level of the vertex (Figs 6 and 7).

\section{DISCUSSION}

Encephalocele is a form of neural tube defect characterized by abnormal protrusion of intracranial contents through a defect in the cranium. They are located in midline, with occipital region being the commonest location followed by the frontoethmoidal location, which is commonly seen in South Asian population. The presentation of encephalocele in parietal region is rare in occurrence. Only few cases of parietal encephaloceles have been reported in the literature, that too of atretic type and only in the postnatal period. Atretic encephaloceles are small, skin-covered subscalp lesions that contain meninges and neural and glial rests with high incidence of venous and midline

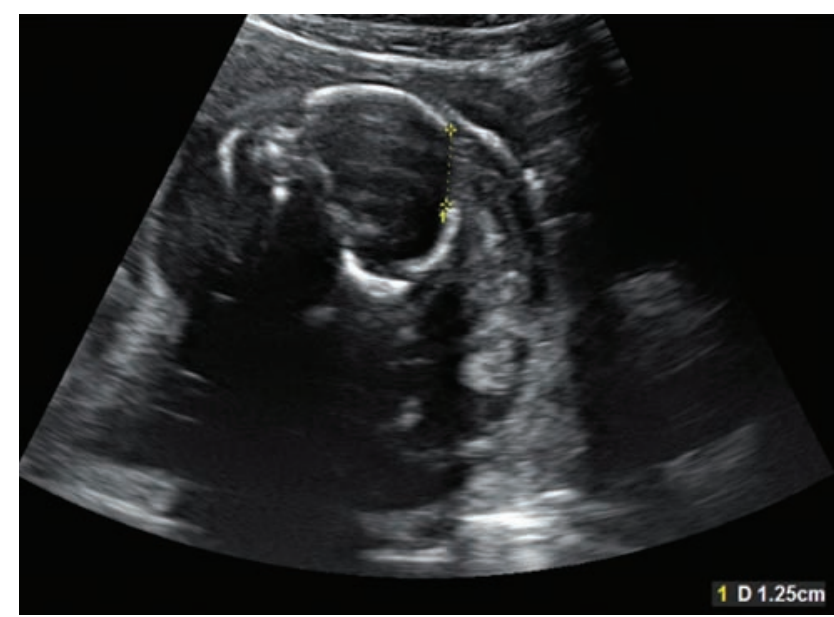

Fig. 3: Ultrasonography image reveals the cranial defect and the herniation

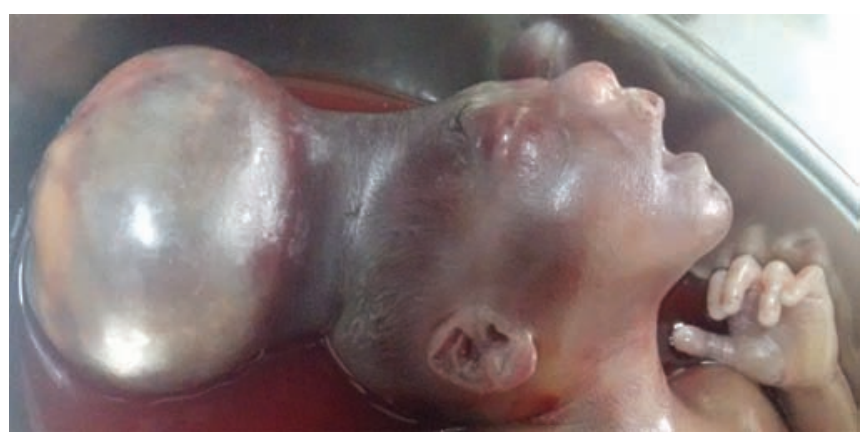

Fig. 5: Pathologic specimen showing swelling arising from the vertex of head with microcephaly

anomalies..$^{2-4}$ In our case, the parietal encephalocele was large in size in contrast with the atretic type and was showing meninges and cerebriform tissue as contents.

The diagnosis of encephalocele can be made antenatally by ultrasonography (USG) and magnetic resonance imaging (MRI). On USG, a solid juxtacortical mass herniating through a cortical defect is suggestive of encephalocele. Careful search for other associated abnormalities in the spine (spina bifida), cranium (hydrocephalus, corpus callosum, cerebral dysgenesis), kidneys (polycystic kidneys), face (cleft lip, cleft palate), and limbs (polydactyly) has to be made. Encephaloceles in occipital region are mainly associated with Dandy-Walker malformation, ArnoldChiari malformation, and Meckel-Gruber syndrome. ${ }^{1}$

Magnetic resonance imaging is predominantly useful for providing excellent detail of cranial defects and better demonstration of herniating contents. It has many advantages over USG in having higher contrast resolution and not being affected by posterior acoustic shadowing caused by overlying bones and by the amount of liquor. ${ }^{1}$ It reveals the brain structures, vascular structures, and associated malformations with much clarity and helps in determining prognosis by the size of herniation. ${ }^{5}$ In our case, MRI was not performed considering the large 


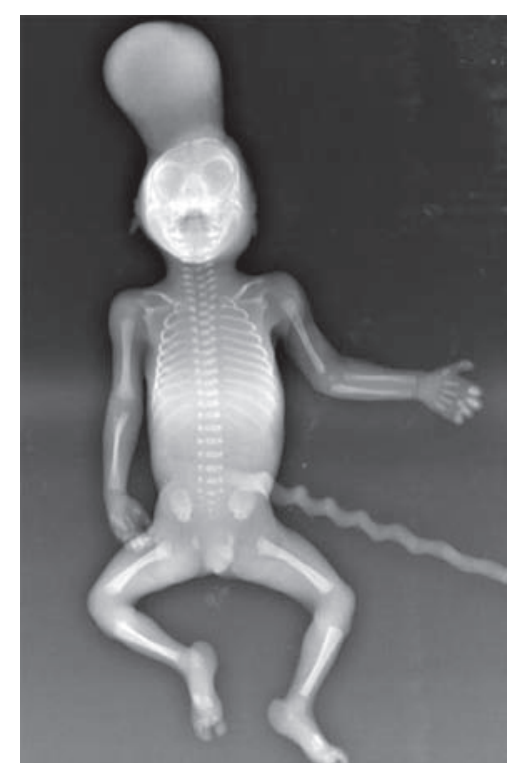

Fig. 6: Anteroposterior view radiograph of the fetus demonstrates soft tissue swelling from vertex region, which is continuous with head

size of cranial defect and the large herniating tissue and well-demarcated cranial defect.

Surgery can be planned postnatally when there is relatively small encephalocele, which is not associated with any other malformations. ${ }^{1}$ In our case, termination of pregnancy was suggested considering the large size of the encephalocele and secondary microcephaly predicting poor prognosis though no associated anomalies were found.

\section{CONCLUSION}

Encephaloceles are herniation of intracranial contents through a defect in the cranium most commonly located in occipital region, and parietal region being the rarest location. Few cases of atretic parietal encephaloceles have been reported in the literature. However, our case was unique in being located in the parietal region and by presenting as a large size lesion with the normal brain parenchyma as major content of herniating sac. It differs from the already reported cases of atretic varieties, in which only small subscalp lesions were found. Characteristic findings are noted on prenatal USG and MRI. The clinical outcome depends on the size of herniation and associated malformations. ${ }^{1}$

\section{CLINICAL SIGNIFICANCE}

Large parietal encephaloceles with the normal brain parenchyma as major content of herniating sac as seen in our case are rare in incidence, with no case being reported

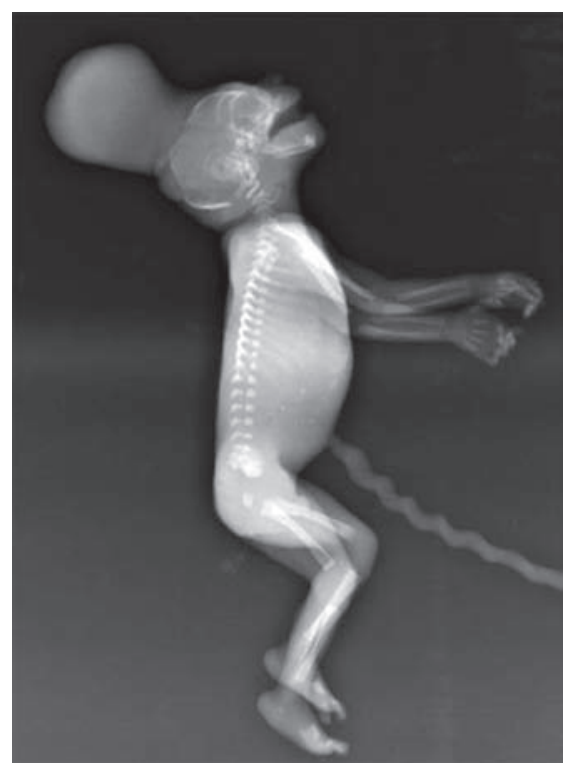

Fig. 7: Lateral view radiograph of the fetus demonstrates soft tissue swelling from vertex region and continuous with head

yet to our knowledge. This case has a poor prognosis as there is a large herniation of brain parenchyma with presence of secondary microcephaly. Hence, continuation of pregnancy is not advisable.

\section{ACKNOWLEDGMENT}

Authors would like to thank all the faculty and staff of the Department of Radiodiagnosis and Department of Obstetrics and Gynecology for their great support.

\section{REFERENCES}

1. Fanny EM, Michael CM, Jeremy JJ, Jill VH. Lumps and bumps on the head in children: use of $\mathrm{CT}$ and MR imaging in solving the clinical diagnostic dilemma. Radiographics 2004 Nov;24(6):1655-1674.

2. Muralidharan CG, Rohit A, Dalbara S. Atretic parietal encephalocele - an unusual diagnosis. Med J Armed Forces India 2013 Jan;69(1):83-85.

3. Patterson RJ, Egelhoff JC, Crone KR, Ball WS. Atretic parietal cephalocoeles revisited: an enlarging clinical and imaging spectrum? AJNR Am J Neuroradiol 1998 Apr;19(4): 791-795.

4. Suheil A, William N, Faozi A, Bishara B, George H. Atretic meningocele: etiopathogenesis, frequency, anomaly associations and imaging findings. Austin J Radiol 2015;2(1):1011.

5. Glenn OA, Barkovich J. Magnetic resonance imaging of the fetal brain and spine: an increasingly important tool in prenatal diagnosis: part 2. AJNR Am J Neuroradiol 2006 Oct;27(9):1807-1814. 